\title{
Synthesis of allyl hydrazine: a comparative study of different methods
}

\author{
Kaija Põhako, ${ }^{\mathrm{a}, \mathrm{b}}$ Kristjan Saal, ${ }^{\mathrm{b}}$ Ilmar Kink, ${ }^{\mathrm{b}}$ Aleksei Bredihhin, ${ }^{\mathrm{a}}$ and Uno Mäeorg ${ }^{\text {a }}$ \\ ${ }^{a}$ Institute of Chemistry, University of Tartu, 2 Jakobi St, 51014 Tartu, Estonia \\ ${ }^{b}$ Institute of Physics, University of Tartu, and Estonian Nanotechnology Competence Center, 142 \\ Riia St, 51014 Tartu, Estonia \\ E-mail: uno@chem.ut.ee
}

Dedicated to Professor Oleg Kulinkovitsch on the occasion of his 60th birthday

\begin{abstract}
In this work different strategies for synthesis of allyl hydrazine were investigated and compared in terms of selectivity, reproducibility and yield. The motivation of this study was mainly the low selectivity and reproducibility of the classical synthetic route, which utilizes allyl halide and hydrazine hydrate as parent substances. In search of more effective methods we have tested the potential of protecting group strategy by exploiting different Boc-hydrazines. We conclude that the approach overcomes the shortcomings of the classical method, as the aforementioned essential synthesis characteristics can be considerably improved. The best results were obtained by employing the route starting with tri-Boc-hydrazine.
\end{abstract}

Keywords: Allyl hydrazine, alkylation, protective group, selectivity

\section{Introduction}

Like other substituted hydrazines allyl hydrazine has a number of applications in pharmacy, agricultural chemistry and organic synthesis, e.g. as a parent substance for synthesis of target compounds. ${ }^{1}$ Double bond offers huge number of possible derivatives as a result of different addition reactions, couplings, oxidations etc. Despite its simple structure allyl hydrazine appears to be rather difficult to synthesize. The classical method uses allylation of hydrazine hydrate with allyl halide, either allyl bromide ${ }^{2}$ or chloride. ${ }^{3}$ The yields are moderate or even satisfactory: $57 \%$ and $70 \%$, respectively; but the papers do not clearly enough state or prove the consistence of the product. Obviously not only mono- but also di- and tri-substituted hydrazines are formed during the process. To improve the selectivity methods based on utilization of orthogonal protective groups have been developed, potentially allowing to synthesize any hydrazine derivative. ${ }^{4}$ However, to the best of our knowledge the synthesis of allyl hydrazine has not been attempted by 
these means. In this work we compare the synthesis of allyl hydrazine via conventional method to these of protective group strategy, starting with Boc-hydrazine, 1, 2-bis-Boc-hydrazine and 1,1,2-tri-Boc-hydrazine.

\section{Results and Discussion}

\section{Synthesis of allyl hydrazine from hydrazine monohydrate (conventional method)}

Experiment 1. First, we followed the protocol developed by Ioffe et al., i.e. the allylation of hydrazine monohydrate with allyl bromide ${ }^{2}$ (Scheme 1). As a result, a mixture of allyl and diallyl hydrazines was formed. The mixture was extracted with water/ethyl ether and the obtained organic fraction was distilled. The yield was poor, indicating that this method could not be efficient for isolating allyl hydrazine, probably due to its quite good solubility in water. Furthermore, the boiling points of the two hydrazine derivatives happen to be rather similar suggesting that they could not be effectively separated by distillation. At this point we must note that available data about the boiling points of allyl hydrazine and diallyl hydrazine are rather inconsistent. For allyl hydrazine the following values have been reported: $122-124{ }^{\circ} \mathrm{C},{ }^{2,5}$ and $102-112{ }^{\circ} \mathrm{C} .{ }^{3}$ And for diallyl hydrazine there are: $60-61{ }^{\circ} \mathrm{C}(35 \mathrm{~mm} \mathrm{Hg}),{ }^{2} \mathrm{bp}<102{ }^{\circ} \mathrm{C}^{3}$ and $145^{\circ} \mathrm{C}$ (752 mm Hg), ${ }^{6}$ respectively. We suspect that the inconsistency rises from the different water content in each case, but considering the huge time gap between these references, additional incomparable factors might be involved.
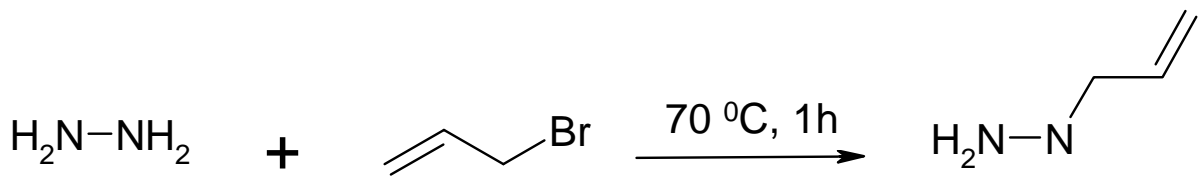

\section{Scheme 1}

Experiment 2. In order to isolate allyl hydrazine we used a different approach, which was novel for the particular synthesis. First, the mixture of allyl hydrazine/diallyl hydrazine was extracted with water/ethyl ether and then the water phase was extracted with chloroform in continuous extractor. The GCMS chromatograms for both ether and water fractions confirmed the presumptions that most of the allyl hydrazine remained in water and mainly diallylhydrazine was extracted into ethyl ether (Figure 1). Gas chromatograms measured for different chloroform fractions showed that first only allyl hydrazine was extracted into ethyl ether, but later-on fractions also contained diallyl hydrazine. The gas chromatograms also indicated the possible disproportionation of allyl hydrazine, as the same chloroform fractions subjected to remeasurements a week later revealed different ratios of allyl hydrazine/diallyl hydrazine. Similar process has been described in the case of tetraalkyl hydrazines, which undergo temperaturedriven disproportionation reactions. ${ }^{7}$ 

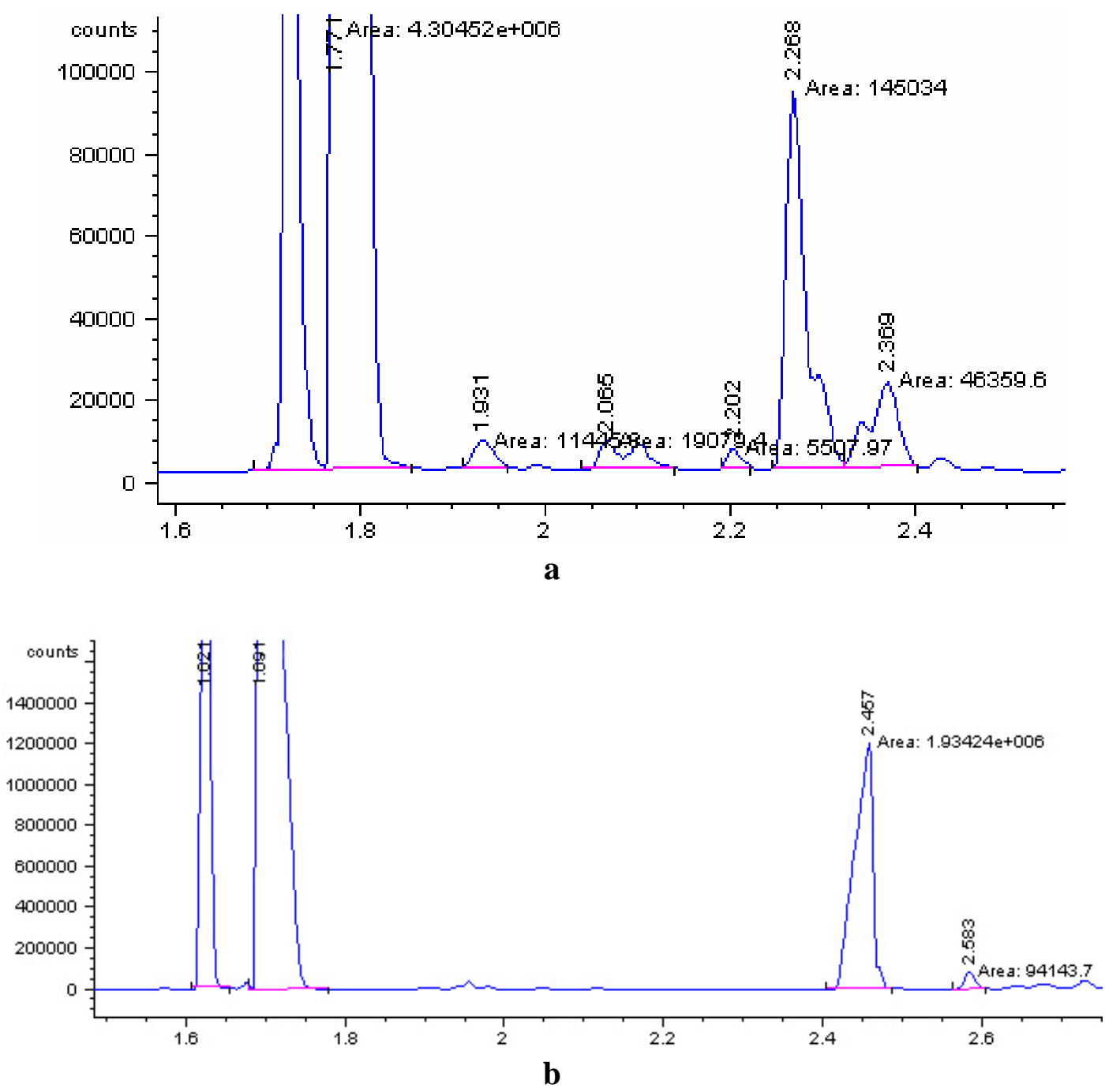

Figure 1. Gas chromatograms of ethyl ether extract (a, peak at $r_{t} 2,268$ min corresponds to monoallyl hydrazine) and chloroform extract (b, peak at $r_{t}$ corresponds to diallylhydrazine).

\section{Synthesis of allyl hydrazine from Boc-hydrazine}

Secondly, we moved to the protecting group strategy, starting with tert-butoxycarbonylhydrazine (Boc-hydrazine), which was allylated in basic medium (Scheme 2). The product depended on the type of the base. For example, triethylamine reacted with Boc-hydrazine, producing the salt and thus inhibited the allylation reaction (Experiment 3). Use of sodium hydrogen carbonate led to 1,1-diallyl-2-Boc-hydrazine $\mathrm{HBr}$ salt (56\%) being too weak base to neutralize the salt (Experiment 4). Consequently, the method is applicable for the selective synthesis of 1,1diallylhydrazine (after the cleavage of the Boc group with TFA/DCM reagent), but formation of allyl hydrazine is not facilitated by this approach. 


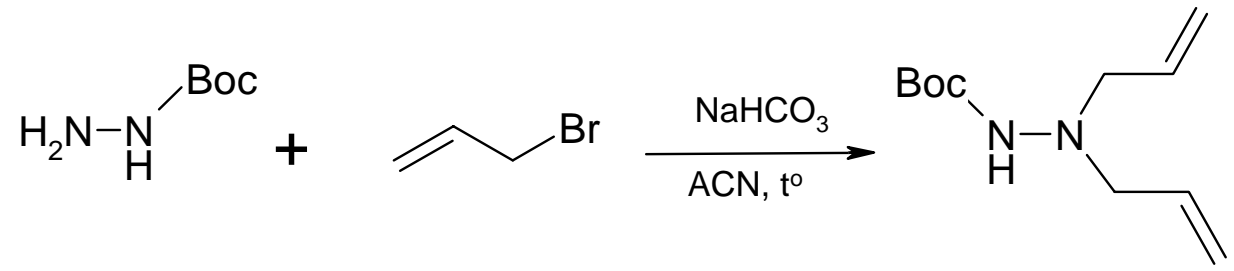

\section{Scheme 2}

\section{Synthesis of allyl hydrazine from 1, 2-bis-Boc-hydrazine}

1, 2-bis-Boc-hydrazine was allylated under phase transfer catalytic conditions (Scheme 3). The results were quite unexpected. Repetitive experiments revealed that allylation of small quantities of 1, 2-bis-Boc-hydrazine (Experiment 5) produced solely monosubstituted product, whereas greater amounts of it (Experiment 6) reproducibly caused the selectivity to disappear, as disubstituted compound was also formed. The reaction was very sensitive to the excess of allyl bromide, but it was not the reason for the loss of selectivity. In order to avoid the local excess of allyl bromide it was added dropwise as toluene solution (allyl bromide/toluene $=1 / 10 \mathrm{v} / \mathrm{v}$ ), but already at the beginning of the addition two products were identified. The mixture was separated by column chromatography, yielding $50 \%$ of 1-allyl-1, 2-bis-Boc-hydrazine. Boc-groups were cleaved with trifluoroacetic acid by a well-known method $^{8}$ (yield 98\%).

Boc

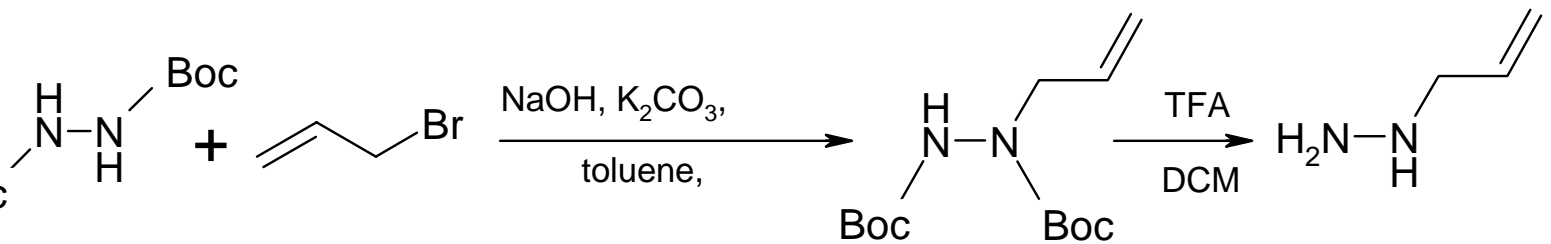

\section{Scheme 3}

A similar approach for the synthesis of allyl hydrazine has been proposed recently. ${ }^{9}$ The work describes the allylation of 1, 2-bis-Boc-hydrazine under phase transfer catalytic conditions (5\% NaOH/toluene/TBAHS, rt, 2.5 h, 71\% yield), which however, differ from the conditions applied in our experiment. They also used $\mathrm{K}_{2} \mathrm{CO}_{3}$ or $\mathrm{Cs}_{2} \mathrm{CO}_{3}$ in DMF. In this case the completion of the reaction took $4 \mathrm{~h}$ and $16 \mathrm{~h}$ respectively, compared to only $10 \mathrm{~min}$ that we achieved. As a result, the authors obtained very good yields (62\% and 88\% respectively) of monosubstituted product and the reaction was claimed to be selective, as the amount of the co-formed disubstituted product was negligible.

\section{Synthesis of allyl hydrazine from 1, 1, 2-tri-Boc-hydrazine}

Experiment 7. 1, 1, 2-tri-Boc-hydrazine ${ }^{4}$ was allylated under phase transfer catalytic conditions with allyl bromide (Scheme 4). The yield of 1-allyl-1, 2, 2-tri-Boc-hydrazine was 82\%. Bocgroups were cleaved with trifluoroacetic acid by a well-known method ${ }^{8}$ (yield 97\%). 
Among the examined methods for the synthesis of allyl hydrazine this is the most sophisticated one because it uses the reagent that only can be made by multi-step and time-consuming synthesis. However, we consider this method the most relevant, because it excludes the formation of co-products.

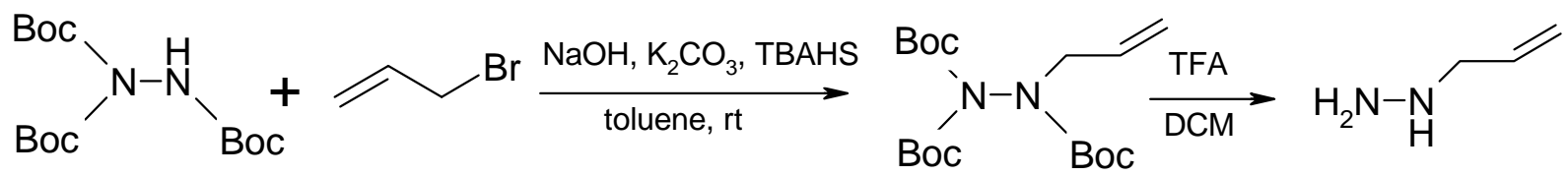

\section{Scheme 4}

The results of the synthesis of allyl hydrazine by different methods are summarized in Table 1.

Table 1. Synthesis of allyl hydrazine by different methods

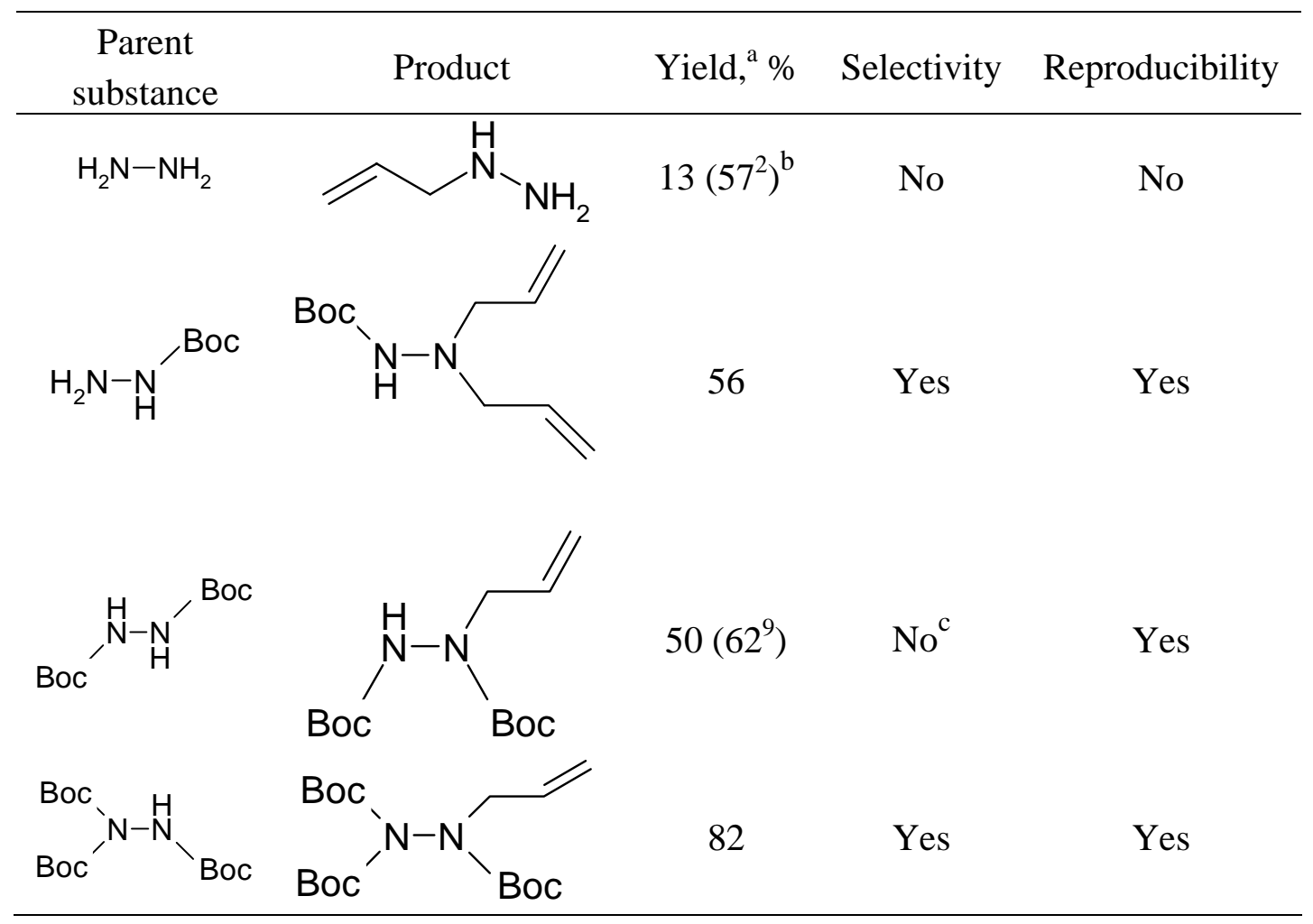

${ }^{\mathrm{a}}$ The yield is provided for the reactions where the product could be isolated. ${ }^{\mathrm{b}}$ The yield applies for the mixture of products, as these could not be effectively separated. ${ }^{\mathrm{c}}$ In the case of small quantities of reagents the reaction was selective, but with greater amounts the selectivity disappeared. For certain amounts of reagents the results were reproducible. 


\section{Conclusions}

Different methods for the synthesis of allyl hydrazine were experimentally tested and compared. For the first time protecting group strategy was successfully applied for the synthesis of allyl hydrazine. The conclusions for each attempted synthetic route are following:

- The conventional method starting from hydrazine monohydrate produces the mixture of allyl hydrazine/diallyl hydrazine. The separation of the mixture is complicated because of the very similar physico-chemical behavior of the two compounds.

- The method starting from Boc-hydrazine selectively yields 1, 1-diallylhydrazine. The formation of allyl hydrazine was not observed.

- The method starting from 1, 2-bis-Boc-hydrazine seems to be contradictory, because small amounts of the reagent $(<1 \mathrm{~g})$ selectively yield allylhydrazine, whereas selectivity disappears while greater amounts are used. The essence of this phenomenon remains unknown.

- Starting from 1, 1, 2-tri-Boc-hydrazine selectively provides allyl hydrazine with good yield (82\%). We find this method to be the most relevant for the synthesis of allyl hydrazine, as the formation of co-products is precluded.

\section{Experimental Section}

General Procedures. ${ }^{1} \mathrm{H}-\mathrm{NMR}(200 \mathrm{MHz})$ and ${ }^{13} \mathrm{C}-\mathrm{NMR}$ (50 MHz) spectra were recorded on Bruker Avance II 200 spectrometer, using $\mathrm{CDCl}_{3}$ or $\mathrm{DMSO}^{-\mathrm{d}_{6}}$ as solvents and tetramethylsilane as an internal standard. IR spectra were recorded on Perkin-Elmer PC 16 FTIR spectrometer; the material under investigation was mixed in $\mathrm{KBr}$ pellets (solids) or as liquid film between $\mathrm{KBr}$ wafers (liquids). Planar chromatography was performed on "Alugram ® ${ }^{\circledR}$ SIL G/ UV 254" silicagel plates provided by Macherey-Nagel. For visualization of the spots the plates were illuminated under UV-light and treated in phosphomolybdic acid (ca 1\% solution in ethanol). Gas chromatograms were recorded on HP 5890A gas chromatograph, column Elite PE-5, $30 \mathrm{~m} \times$ $0.25 \mathrm{~mm}$; column temperature $120{ }^{\circ} \mathrm{C}$, injector temperature $200{ }^{\circ} \mathrm{C}$ and detector (FID) temperature $200{ }^{\circ} \mathrm{C}$. GS-MS analyses were performed on Varian Saturn 2000 instrument, column DB-5 $30 \mathrm{~m} \times 0.25 \mathrm{~mm}$; column temperature $120^{\circ} \mathrm{C}$, injector temperature $200{ }^{\circ} \mathrm{C}$.

\section{Synthesis of allyl hydrazine ${ }^{2}$ from hydrazine monohydrate}

Experiment $1.55 \mathrm{ml}\left(1.135 \mathrm{~mol}, 7\right.$ equiv) of hydrazine hydrate was preheated to $37^{\circ} \mathrm{C}$ and 14 $\mathrm{ml}$ of allyl bromide ( $0.162 \mathrm{~mol}, 1$ equiv) was gradually added (approx. one drop per three seconds) by gentle stirring while maintaining the temperature of the reaction mixture at $37-40^{\circ} \mathrm{C}$. Then the mixture was heated for 1 hour at $70^{\circ} \mathrm{C}$. The reaction was monitored with TLC (eluent: methanol) and indicated to the formation of two new less polar products. After heating the reaction mixture was neutralized with sodium hydrogen carbonate ( $21.5 \mathrm{~g}, 1.5$ equiv). Then 50 
$\mathrm{ml}$ of water was added and the mixture was extracted with ethyl ether $(4 \times 50 \mathrm{ml})$. Organic fractions were combined and dried over anhydrous magnesium sulphate. The mixture was filtered and the solution was concentrated under reduced pressure. The obtained yellowish viscous liquid was distilled and the following fractions were collected: $1.281 \mathrm{~g}$, bp $65-70^{\circ} \mathrm{C}(300$ $\mathrm{mm} \mathrm{Hg}$ ), and $1.401 \mathrm{~g}$, bp $50-55^{\circ} \mathrm{C}$ (200 mm Hg). NMR spectra of both fractions were very similar and distinction between allyl hydrazine and diallyl hydrazine could not be made. Fraction 1: ${ }^{13} \mathrm{C}-\mathrm{NMR}: \delta=63.7\left(\mathrm{HN}-\mathrm{CH}_{2}\right), 118.4\left(\mathrm{HC}=\underline{\mathrm{CH}}_{2}\right), 134.8\left(\mathrm{HC}=\mathrm{CH}_{2}\right) ;{ }^{1} \mathrm{H}-\mathrm{NMR}: \delta=2.95(\mathrm{~s}, 1 \mathrm{H}$, $\mathrm{NH}), 3.19$ (d, 2H, J=5.6 Hz, N-CH ), 5.19-5.28 (m, 2H, $\left.\mathrm{CH}_{2}\right), 5.82-6.02(\mathrm{~m}, 1 \mathrm{H}, \mathrm{CH})$. Fraction 2: ${ }^{13} \mathrm{C}-\mathrm{NMR}: \delta=63.7\left(\mathrm{HN}-\mathrm{CH}_{2}\right), 118.3\left(\mathrm{HC}=\mathrm{CH}_{2}\right), 134.8\left(\mathrm{HC}=\mathrm{CH}_{2}\right) ;{ }^{1} \mathrm{H}-\mathrm{NMR}: \delta=2.94(\mathrm{~s}, 1 \mathrm{H}$, $\mathrm{NH}$ ), 3.19 (d, 2H, J=7.4 Hz, N-CH ), 5.18-5.27 (m, 2H, $\mathrm{CH}_{2}$ ), 5.82-6.02 (m, 1H, CH).

Experiment 2. The same reaction (see Experiment 1) was repeated with the following amounts of reagents: $60.7 \mathrm{ml}(1.25 \mathrm{~mol})$ of hydrazine monohydrate and $24 \mathrm{ml}(0.277 \mathrm{~mol})$ of allyl bromide. After the heat treatment the mixture was neutralized with $13.34 \mathrm{~g}$ of sodium hydrogen carbonate ( $0.16 \mathrm{~mol}, 1.7$ equiv). Then $60 \mathrm{ml}$ of water was added and the mixture was extracted with ethyl ether $(3 \times 50 \mathrm{ml})$. Organic fractions were combined and dried first over anhydrous magnesium sulphate and then over calcium hydride. The mixture was filtered and the filtrate was concentrated under reduced pressure. The obtained viscous liquid was distilled over calcium hydride and $0.308 \mathrm{~g}$ of product was collected, bp $50-55^{\circ} \mathrm{C}$ (148 $\mathrm{mm} \mathrm{Hg}$ ). Both the obtained liquid and water phase of the extraction were analyzed with GC-MS, indicating the former being diallyl hydrazine and the other containing allyl hydrazine. For the obtained liquid NMR spectrum was recorded. ${ }^{13} \mathrm{C}-\mathrm{NMR}: \delta=63.7\left(\mathrm{HN}-\mathrm{CH}_{2}\right), 118.3\left(\mathrm{HC}=\underline{C H}_{2}\right), 134.8\left(\mathrm{HC}=\mathrm{CH}_{2}\right) ;{ }^{1} \mathrm{H}-\mathrm{NMR}: \delta=$ 2.94 (s, 1H, NH), 3.21, (d, 2H, J=8.2 Hz, N-CH $)$, 5.19-5.28 (m, 2H, $\left.\mathrm{CH}_{2}\right), 5.82-6.03$ (m, 1H, $\mathrm{CH})$. GC-MS: $\mathrm{NH}_{2}-\mathrm{NH}-\mathrm{CH}_{2}-\mathrm{CH}=\mathrm{CH}_{2},\left[\mathrm{MH}^{+}\right]$: 73, $\mathrm{HN}-\mathrm{N}\left(\mathrm{CH}_{2}-\mathrm{CH}=\mathrm{CH}_{2}\right)_{2},\left[\mathrm{MH}^{+}\right]: 113$.

$25 \mathrm{ml}$ of the water phase of the extraction was extracted with chloroform for 10 hours in continuous extractor. Three chloroform fractions were collected and analyzed with GC. Chloroform was distilled from the first fraction where allyl hydrazine concentration was the highest. $3 \mathrm{ml}$ of the obtained yellowish viscous liquid was dissolved in dichloromethane, dried first with magnesium sulphate and then with calcium hydride. 0.633 g (yield 13\%) of product was obtained after removal of dichloromethane and by distillation. The product was subjected to NMR and GC analyses and identified as the mixture of allyl hydrazine and diallyl hydrazine. ${ }^{13} \mathrm{C}-\mathrm{NMR}: \delta=63.7\left(\mathrm{HN}-\mathrm{CH}_{2}\right), 116.3\left(\underline{\mathrm{CH}}=\mathrm{CH}_{2}\right.$, allyl hydrazine $), 118.4$ (= $\mathrm{CH}_{2}$, diallyl hydrazine), 134.5 ( $\underline{\mathrm{CH}}=\mathrm{CH}_{2}$, diallyl hydrazine), 136.3 ( $\underline{\mathrm{CH}}=\mathrm{CH}_{2}$, allyl hydrazine).

\section{Synthesis of allyl hydrazine from Boc-hydrazine}

Experiment 3. $2.334 \mathrm{~g}(0.0177 \mathrm{~mol})$ of Boc-hydrazine was dissolved in $25 \mathrm{ml}$ of acetonitrile and $1.5 \mathrm{ml}(0.0174 \mathrm{~mol})$ of allyl bromide was added. $2.5 \mathrm{ml}(0.0178 \mathrm{~mol})$ of triethylamine was introduced to the mixture in order to neutralize the $\mathrm{HBr}$ formed during the reaction. The mixture was heated under reflux. After 1 hour only traces of two products were detected by TLC (eluent: EtOAc:hexane 1:2). The obtained mixture was not subjected to further investigations. 
Experiment 4. The reaction (see Experiment 3) was repeated with the same amounts of reagents but the reaction mixture was neutralized with $\mathrm{NaHCO}_{3}$ (instead of triethylamine). After one hour the TLC analysis showed two products, but the starting material BocNHNH $\mathrm{N}_{2}$ was still present. In order to complete the reaction additional $1.5 \mathrm{ml}(0.0174 \mathrm{~mol}, 1$ equiv) of allyl bromide was added. After 1.5 hour of heating the reaction came to completion and TLC showed only one product. The reaction mixture was filtered and concentrated under reduced pressure. The obtained yellow viscous liquid was crystallized in dichloromethane:hexane:methanol and $2.350 \mathrm{~g}$ of product was collected (yield 56\%). NMR analyses confirmed the product being 1, 1-diallyl-2Boc-hydrazine $\mathrm{HBr}$ salt ${ }^{10} .{ }^{13} \mathrm{C}-\mathrm{NMR}: \delta=28.2\left(\mathrm{CH}_{3}, \mathrm{Boc}\right), 61.1\left(\mathrm{NH}-\mathrm{CH}_{2}\right), 83.9\left(\mathrm{O}-\mathrm{C}-(\mathrm{CH})_{3}\right)$, 126.3, $126.8\left(\mathrm{CH}=\mathrm{CH}_{2}\right), 153.5(\mathrm{C}=\mathrm{O}) .{ }^{1} \mathrm{H}-\mathrm{NMR}: \delta=1.45$ (s, 9H, Boc), 4.33 (d, 4H, J = $7.0 \mathrm{~Hz}$, $\left.\mathrm{NH}-\mathrm{CH}_{2}\right)$, 5.48-5.80 (m, 2H, = $\left.\mathrm{CH}_{2}\right)$, 6.06-6.27 (m, 2H, CH), 9.69 (s, 2H, NH).

\section{Synthesis of allyl hydrazine from 1, 2-bis-Boc-hydrazine}

Experiment 5. $75 \mathrm{mg}(0.323 \mathrm{mmol})$ of 1, 2-bis-Boc-hydrazine was dissolved in $1 \mathrm{ml}$ of toluene and $30 \mu \mathrm{l}$ of allyl bromide ( $0.339 \mathrm{mmol}, 1.05$ equiv) was added to the solution. The reaction was conducted at room temperature under PTC conditions (Phase Transfer Catalysis) using $89 \mathrm{mg}$ (0.646 mmol, 2 equiv) of $\mathrm{K}_{2} \mathrm{CO}_{3}, 45 \mathrm{mg}$ (1.131 mmol, 3.5 equiv) of $\mathrm{NaOH}$ and $12 \mathrm{mg}(0.1$ equiv) of tetrabutylammonium hydrogen sulfate (TBAHS). The reaction was monitored with TLC (eluent: EtOAc:hexane 1:8), which showed its coming to completion in 10 minutes. The TLC analysis indicated that the primary substance was consumed totally and one dominant product was formed - probably 1-allyl-1, 2-di-Boc-hydrazine. The co-product, much less in quantity, was less polar and was probably 1, 2-diallyl-1, 2-di-Boc-hydrazine. As the experiment was qualitative the products were not separated.

Experiment 6. The Experiment 5 was repeated with greater amounts of the reagents. $10 \mathrm{~g}(0.043$ mol) of 1, 2-bis-Boc-hydrazine was dissolved in $160 \mathrm{ml}$ of toluene and $3.9 \mathrm{ml}$ of allyl bromide (1.05 equiv) was gradually added to the solution. The reaction was conducted at room temperature under PTC conditions using $11.868 \mathrm{~g}$ (2 equiv) of $\mathrm{K}_{2} \mathrm{CO}_{3}, 6.027 \mathrm{~g}$ (3.5 equiv) of $\mathrm{NaOH}$ and $1.466 \mathrm{~g}$ (0.1 equiv) of TBAHS. The reaction was monitored with TLC (eluent: EtOAc:hexane 1:8) and it took 10 minutes to completion. The TLC analysis indicated to the total consumption of the starting material and to the formation of two products in equal portions. The mixture was separated by column chromatography. First, EtOAc:hexane was used to elute the less polar disubstituted product, resulting in crystallization of the monosubstituted product on top of the chromatography column. Methanol was then used to elute the monosubstituted product, yielding 5.879 g of 1-allyl-1,2-bis-Boc-hydrazine ${ }^{10}$ (50\%), as confirmed by NMR and IR. ${ }^{13} \mathrm{C}$ NMR: $\delta=28.8$ (Boc), $52.9\left(\mathrm{NH}-\mathrm{CH}_{2}\right), 81.3\left(\mathrm{O}-\mathrm{C}-(\mathrm{CH})_{3}\right), 117.5\left(\mathrm{CH}=\underline{\mathrm{CH}}_{2}\right), 133.3\left(\underline{\mathrm{CH}}=\mathrm{CH}_{2}\right)$, $155.2(\mathrm{C}=\mathrm{O}) .{ }^{1} \mathrm{H}-\mathrm{NMR}: \delta=1.47$ (s, 18H, Boc), 4.05 (d, 2H, J = 4.6 Hz NH-C $\underline{\mathrm{H}}_{2}$ ), 5.13-5.22 (m, $\left.2 \mathrm{H},=\mathrm{CH}_{2}\right), 5.74-5.96(\mathrm{~m}, 1 \mathrm{H}, \mathrm{CH}), 6.55$ (s, $\left.1 \mathrm{H}, \mathrm{NH}\right) . \mathrm{IR}: 3290 \mathrm{~cm}^{-1}(\mathrm{NH}), 3079 \mathrm{~cm}^{-1}\left(=\mathrm{CH}_{2}\right)$, $2982 \mathrm{~cm}^{-1}, 2936 \mathrm{~cm}^{-1}\left(\mathrm{CH}_{2}, \mathrm{CH}_{3}\right), 1744 \mathrm{~cm}^{-1}(\mathrm{C}=\mathrm{O}), 1682 \mathrm{~cm}^{-1}$ (broad, C=C, NH def.), $1148 \mathrm{~cm}^{-1}$ (C-O). To remove the protective groups the crystals of 1-allyl-1, 2-bis-Boc-hydrazine were dissolved in a mixture of $\mathrm{CH}_{2} \mathrm{Cl}_{2}$ : TFA 2:1 (4 ml of the solution was used for $1 \mathrm{mmol}$ of 1-allyl- 
1,2-bis-Boc-hydrazine). The TLC analysis indicated the completion of the reaction (formation of trifluoroacetate) after one hour. Then the solvent was removed under reduced pressure, remaining $12.1 \mathrm{~g}$ of yellowish viscous oil. The oil was treated with $70 \mathrm{ml}$ of $\mathrm{NaOH}$ (ca 5 equiv) water solution in order to form allyl hydrazine as free base. The solution was extracted with ethyl ether $(4 \times 50 \mathrm{ml})$. Organic fractions were combined and dried over anhydrous magnesium sulphate. The solution was filtered and concentrated under reduced pressure. $1.521 \mathrm{~g}$ of allyl hydrazine was obtained (yield of the removal of protective groups 98\%). IR: $3238 \mathrm{~cm}^{-1}(\mathrm{NH})$, $3079 \mathrm{~cm}^{-1}$ (=CH$), 2974 \mathrm{~cm}^{-1}, 2879 \mathrm{~cm}^{-1}\left(\mathrm{CH}_{2}, \mathrm{CH}_{3}\right), 1675 \mathrm{~cm}^{-1}$ (broad, C=C, NH def.), 1199 $\mathrm{cm}^{-1}(\mathrm{C}-\mathrm{N})$.

\section{Synthesis of allyl hydrazine from 1, 1, 2-tri-Boc-hydrazine}

Experiment 7. $300 \mathrm{mg}(0.904 \mathrm{~mol})$ of tri-Boc-hydrazine was dissolved in $1 \mathrm{ml}$ of toluene and $0.082 \mathrm{ml}$ of allyl bromide ( $0.949 \mathrm{mmol}, 1.05$ equiv) was gradually added to the solution. The reaction proceeded at room temperature under PTC conditions using $249 \mathrm{mg}$ (1.808 mmol, 2 equiv) of $\mathrm{K}_{2} \mathrm{CO}_{3}, 126 \mathrm{mg}$ ( $3.164 \mathrm{mmol}, 3.5$ equiv) of $\mathrm{NaOH}$ and $31 \mathrm{mg}$ (0.09 mmol, 0.1 equiv) of TBAHS. The reaction was completed in 15 minutes. $5 \mathrm{ml}$ of water was added to the solution and it was extracted with ethyl ether $(3 \times 5 \mathrm{ml})$. Organic fractions were combined, washed with saturated $\mathrm{NaCl}$ solution and dried over anhydrous magnesium sulphate. The reaction solution was filtered and concentrated under reduced pressure. $275 \mathrm{mg}$ of viscous liquid was obtained (yield 82\%) and NMR spectrum confirmed it to be 1-allyl-1,2,2-tri-Boc-hydrazine. ${ }^{13} \mathrm{C}-\mathrm{NMR}$ : $\delta$ $=28.1\left(\mathrm{CH}_{3}, \mathrm{Boc}\right), 51.9\left(\mathrm{NH}-\mathrm{CH}_{2}\right), 83.1\left(\mathrm{O}-\underline{\mathrm{C}}-(\mathrm{CH})_{3}\right), 118,8\left(\mathrm{CH}=\underline{\mathrm{CH}}_{2}\right), 132,5\left(\underline{\mathrm{CH}}=\mathrm{CH}_{2}\right)$, $150.3(\mathrm{C}=\mathrm{O}) .{ }^{1} \mathrm{H}-\mathrm{NMR}: \delta=1,49$ (s, 27H, Boc), 4.06 (d, 2H, J=6,4 Hz, NH-CH ), 5.10-5.23 (m, $2 \mathrm{H},=\mathrm{CH}_{2}$ ), 5.78-5.99 (m, 1H, CH). HRMS (ESI) m/z calcd. for $\mathrm{C}_{18} \mathrm{H}_{33} \mathrm{~N}_{2} \mathrm{O}_{6}[\mathrm{MH}]^{+}: 373,23331$; found: 373,23331. The deprotection of Boc groups gave the pure allylhydrazine in $97 \%$ yield, which NMR spectra were identical with the ones of the product from Experiment 6.

\section{Acknowledgements}

We acknowledge the Estonian Science Foundation for financial support (grants no 6707, 6537 and 7102). We also acknowledge Erkki Mäeorg and Alar Aluvee for kind help with GC and GCMS analyses.

\section{References and Notes}

1. Ragnarsson, U. Chem. Soc. Rev. 2001, 30, 205.

2. Ioffe, B. V.; Sergeeva, Z. I.; Kochetov, A. P. Zhurnal Organicheskoi Khimii 1967, 3, 983.

3. Nakagawa, M; Sogawa, M; Shimada, K. JP Pat. 07112963 A2, 1995.

4. Mäeorg, U.; Grehn, L.; Ragnarsson, U. Angew. Chem. Int. Ed. 1996, 35, 2626.

5. Gabriel, S. Ber. 1914, 47, 3028. 
6. Diels, O. Ber. 1923, 56, 1933.

7. Westphal, O.; Eucken, M. Ber. 1943, 1137.

8. Greene, T. W.; Wuts, P. G. M. Protective Groups in Organic Synthesis $3^{\text {rd }}$ Edn., Wiley: New York, 1999, pp 518-525.

9. Rasmussen, L. K. J. Org. Chem. 2006, 71, 3627.

10. Bredihhin, A. Mäeorg, U. Org. Lett. 2007, 9, 4975. 